\title{
Circulating growth factor concentrations and breast cancer risk: a nested case- control study of IGF-1, IGFBP-3, and breast cancer in a family-based cohort
}

Kelsey R. Monson ${ }^{1}$, Mandy Goldberg ${ }^{1}$, Hui-Chen Wu ${ }^{2,3}$, Regina M. Santella ${ }^{2,3}$, Wendy K. Chung ${ }^{3,4,5}$ and Mary Beth Terry ${ }^{1,2,3^{*}}$ (iD

\begin{abstract}
Background: Insulin-like growth factor 1 (IGF-1) and binding protein 3 (IGFBP-3) are associated with breast cancer in women at average risk of cancer. Less is known whether these biomarkers also predict risk in women with breast cancer family history.

Methods: We conducted a nested case-control study within the New York site of the Breast Cancer Family Registry (BCFR, $n=80$ cases, 156 controls), a cohort enriched for breast cancer family history. Using conditional logistic regression, we estimated the association between IGF-1 and IGFBP-3 levels and breast cancer risk and examined whether this risk differed by predicted absolute breast cancer risk based on pedigree models.

Results: The overall association between IGF-1 or IGFBP-3 elevation ( $\geq$ median in controls) and breast cancer risk was elevated, but not statistically significant (IGF-1 OR $=1.37,95 \% \mathrm{Cl}=0.66-2.85$; IGFBP-3 OR $=1.62,95 \% \mathrm{Cl}=0.81-$ 3.24). Women with elevated predicted absolute 10-year risk $\geq 3.4 \%$ and elevated IGFBP-3 ( $\geq$ median) had more than a 3 -fold increased risk compared to women with lower predicted absolute 10 -year risk $(<3.4 \%)$ and low IGFBP$3(\mathrm{OR}=3.4795 \% \mathrm{Cl}=1.04-11.6)$.
\end{abstract}

Conclusions: These data offer some support that the overall magnitude of the associations between IGF-1 and IGFBP3 seen in average risk cohorts may be similar in women enriched with a strong breast cancer family history.

Keywords: IGF-1, IGFBP-3, Breast cancer, Risk model, Family history

\section{Background}

Insulin-like growth factor (IGF-1) and its primary binding protein (IGFBP-3) are known risk factors for breast cancer due to their ability to stimulate mitosis and suppress programmed cell death [1]. Studies have shown that both breast cancer development and recurrence are

\footnotetext{
* Correspondence: mt146@columbia.edu

'Department of Epidemiology, Mailman School of Public Health, Columbia University, 722 West 168th Street, New York, NY 10032, USA

2Department of Environmental Health Sciences, Mailman School of Public Health, Columbia University, 722 West 168th Street, New York, NY 10032, USA Full list of author information is available at the end of the article
}

associated with IGF-1 and IGFBP-3 levels in women [2, $3]$. To date, these studies have been in cohorts comprised of women from the general population who are therefore at average risk of cancer. Women with a family history of breast cancer are two to four times more likely to develop the disease compared to women with no family history [4]. With few exceptions, there exists limited data regarding whether IGF-1/IGFBP-3 biomarkers may be associated with cancer in women at high risk of breast cancer [2]. Most epidemiological cohorts are not powered to address the association between risk factors

C The Author(s). 2020 Open Access This article is licensed under a Creative Commons Attribution 4.0 International License, which permits use, sharing, adaptation, distribution and reproduction in any medium or format, as long as you give appropriate credit to the original author(s) and the source, provide a link to the Creative Commons licence, and indicate if changes were made. The images or other third party material in this article are included in the article's Creative Commons licence, unless indicated otherwise in a credit line to the material. If material is not included in the article's Creative Commons licence and your intended use is not permitted by statutory regulation or exceeds the permitted use, you will need to obtain permission directly from the copyright holder. To view a copy of this licence, visit http://creativecommons.org/licenses/by/4.0/ The Creative Commons Public Domain Dedication waiver (http://creativecommons.org/publicdomain/zero/1.0/) applies to the data made available in this article, unless otherwise stated in a credit line to the data. 
and breast cancer across the spectrum of predicted absolute breast cancer risk.

\section{Methods \\ Study population}

Within the New York site of the Breast Cancer Family Registry (BCFR), we prospectively followed a sub-cohort of women unaffected with breast cancer at study entry. The New York site of the BCFR recruited family members with multiple instances of breast or ovarian cancer to construct a family-based registry to assess risk due to a woman's familial risk profile (FRP) (for full study details, see [4-6]). In this nested case-control study within the larger New York BCFR cohort, 80 prospectively ascertained invasive breast cancer cases were identified and matched to 156 controls by age, ethnicity, and follow-up time. We determined breast cancer diagnoses through self-report, medical record linkage, or family member report. Cases and controls must have had both breasts at baseline and an age at baseline interview of $\leq 70$ years. While the history of prior breast cancer was an exclusion criterion for entry into this unaffected BCFR cohort, both cases and controls could have had prior other non-breast cancers. All women participating in the BCFR provided written informed consent, and the study was approved by the Columbia University Medical Center Institutional Review Board.

\section{Biomarker assessment}

We collected a 30-mL blood sample at baseline, which was processed and stored at the New York site of the BCFR [6]. To assess absolute levels of biomarkers in cases versus controls, we measured IGF-1 and IGFBP-3 concentrations (in $\mathrm{ng} / \mathrm{mL}$ ) in stored plasma at the Irving Institute for Clinical and Translational Research Core Biomarkers Lab at Columbia University. We measured IGF-1 using a chemiluminescent immunoassay (CLIA) on the Immulite 1000 automated platform (Siemens Healthcare Diagnostics, Deerfield, IL). Two subjects in this analysis had IGF-1 levels below $25 \mathrm{ng} / \mathrm{mL}$, the limit of detection of the assay; the IGF-1 value for these women was set to $25 \mathrm{ng} / \mathrm{mL}$. The IGF-1 inter-assay coefficient of variation $(\mathrm{CV})$, which we calculated from a pooled sample, was $4.6 \%$. We measured IGFBP-3 using a Human IGFBP-3 Quantikine enzyme-linked immunosorbent assay (ELISA) kit (R\&D Systems, Minneapolis, MN). The IGFBP-3 inter-assay CV from a pooled sample was $4.8 \%$. The laboratory was blinded to case-control status.

\section{Statistical analysis}

We calculated each woman's 10-year absolute risk of breast cancer using the BOADICEA (Breast and Ovarian Analysis of Disease Incidence and Carrier Estimation
Algorithm) risk model [7, 8]. In our analyses, the risk score was analyzed as both a continuous and dichotomized variable to differentiate between women at "average" and "high" risk. A 10-year risk above 3.4\% is considered "elevated" per National Comprehensive Cancer Network (NCCN) Clinical Practice Guidelines; therefore, we dichotomized BOADICEA to $<3.4 \%$ and $\geq 3.4 \%$ [9].

We performed conditional logistic regression on the 1 : 2 matched sets of cases and controls to estimate the breast cancer risk for women with high circulating IGF1 or IGFBP-3 biomarker levels compared to women with low levels. We defined elevated biomarkers as greater than or equal to the median value in controls $(93.95 \mathrm{ng} /$ $\mathrm{mL}$ for IGF-1; $2009 \mathrm{ng} / \mathrm{mL}$ for IGFBP-3) and assessed risk for both elevated and continuous log-transformed biomarker levels. To test for the interaction between biomarker levels and BOADICEA score, we first tested for linearity of the biomarker level. We then used a cross-product term to assess multiplicative interaction and examined interaction on the additive scale using relative excess risk due to interaction (RERI). We adjusted for baseline covariates including obesity (body mass index $\geq 30 \mathrm{~kg} / \mathrm{m}^{2}$ ), smoking and alcohol consumption, menopausal status, and BOADICEA score.

\section{Results}

Table 1 presents the baseline characteristics of the participants in the nested case-control study compared to the other participants in the unaffected cohort. Participants in this analysis were slightly older (mean age, casecontrol $=45.8$ years; cohort $=42.8$ years), less ethnically diverse (\% white, case-control $=86.9 \%$; cohort $=65.7 \%$ ), and at higher risk of breast cancer (mean BOADICEA score, case-control $=6.76 \%$; cohort $=4.88 \%$ ). Cases and controls were comparable across all covariates except for BOADICEA risk scores, with cases demonstrating higher scores than controls (Table 1). Cases and controls did not have significantly different IGF-1 (geometric mean $=$ $93.9 \mathrm{ng} / \mathrm{mL}, \mathrm{SD}=1.45$ in controls; geometric mean = $95.0 \mathrm{ng} / \mathrm{mL}, \mathrm{SD}=1.46$ in cases) or IGFBP-3 (geometric mean $=1960 \mathrm{ng} / \mathrm{mL}, \mathrm{SD}=1.32$ in controls; geometric mean $=2069 \mathrm{ng} / \mathrm{mL}, \mathrm{SD}=1.25$ in cases) levels (Table 1 ).

The risk of breast cancer was elevated across models with continuous biomarker measures except for the adjusted model for continuous IGF-1 (OR $=0.77,95 \% \mathrm{CI}$ $0.26-2.31$, Table 2). We also saw increased risk with elevated biomarker levels, with an OR of 1.37 (95\% CI $0.66-2.85)$ in the adjusted model for elevated IGF-1 and an OR of 1.62 (95\% CI 0.81-3.24) for elevated IGFBP-3 (Table 2). We also examined the ratio of IGF-1/IGFBP3 , which was not associated with breast cancer risk in our sample (data not shown). 
Table 1 Baseline characteristics of nested case-control participants by breast cancer status $(n=236)$, all other participants in the full unaffected cohort $(n=1729)$, New York Site of the BCFR

\begin{tabular}{|c|c|c|c|c|}
\hline & $\begin{array}{l}\text { Cases: women with } \\
\text { breast cancer, } N=80 \\
N(\%)\end{array}$ & $\begin{array}{l}\text { Matched controls: women } \\
\text { without breast cancer, } N=156 \\
N(\%)\end{array}$ & $\begin{array}{l}\text { Nested case-control } \\
\text { total, } N=236 \\
N(\%)\end{array}$ & $\begin{array}{l}\text { Unaffected cohort, } \\
N=1729 \\
N(\%)\end{array}$ \\
\hline \multicolumn{5}{|l|}{ Age at blood draw } \\
\hline Mean years (s.d.) & $46.2(10.3)$ & $45.5(10.9)$ & $45.8(10.7)$ & $42.8(13.2)^{b}$ \\
\hline \multicolumn{5}{|l|}{ Ethnicity } \\
\hline Non-Hispanic White & $71(88.8)$ & $134(85.9)$ & $205(86.9)$ & $1136(65.7)$ \\
\hline Hispanic & $9(11.3)$ & $20(12.8)$ & $29(12.3)$ & $414(23.9)$ \\
\hline Others & $0(0)$ & $2(1.3)$ & $2(0.9)$ & $179(10.4)$ \\
\hline \multicolumn{5}{|l|}{$\mathrm{BMl}$} \\
\hline Mean $\mathrm{kg} / \mathrm{m}^{2}$ (s.d.) & $24.6(4.5)$ & $23.8(4.4)$ & $24.1(4.4)$ & $25.2(5.6)$ \\
\hline \multicolumn{5}{|l|}{ Menopausal status } \\
\hline Pre-menopausal & $52(65.0)$ & $112(71.8)$ & $164(71.9)$ & $1129(67.0)$ \\
\hline Post-menopausal & $27(33.8)$ & $37(23.7)$ & $64(28.1)$ & $557(33.0)$ \\
\hline \multicolumn{5}{|l|}{ Smoking status } \\
\hline Current & $6(7.5)$ & $14(9.0)$ & $20(8.5)$ & $153(8.9)$ \\
\hline Former & $29(36.3)$ & $44(28.2)$ & $73(31.1)$ & $513(29.8)$ \\
\hline Never & $44(55.0)$ & $98(62.8)$ & $142(60.4)$ & $1054(61.3)$ \\
\hline \multicolumn{5}{|l|}{ Alcohol consumption } \\
\hline Current & $27(33.8)$ & $58(37.2)$ & 85 (36.5) & $505(29.4)$ \\
\hline Former & $17(21.3)$ & $24(15.4)$ & $41(17.6)$ & $505(16.7)$ \\
\hline Never & $36(45.0)$ & $71(45.5)$ & $107(45.9)$ & $943(54.9)$ \\
\hline \multicolumn{5}{|l|}{ BOADICEA score } \\
\hline Mean (s.d.) & $7.94(7.2)$ & $5.55(5.0)$ & $6.76(6.84)$ & $4.88(6.1)$ \\
\hline Average risk $(<3.4 \%)$ & 19 (23.8) & $56(35.9)$ & $75(32.5)$ & $841(48.6)$ \\
\hline Elevated risk ( $\geq 3.4 \%$ ) & $61(76.3)$ & $95(60.9)$ & $156(67.5)$ & $888(51.4)$ \\
\hline \multicolumn{5}{|l|}{ IGF-1 level (ng/mL) } \\
\hline Geometric mean (geometric s.d.) & $95.0(1.46)$ & $93.9(1.45)$ & $94.3(1.45)$ & $N / A$ \\
\hline Median (IQR) & $99.6(45.6)$ & $94.0(45.8)$ & $96.4(45.9)$ & $N / A$ \\
\hline$<93.95$ & $34(42.5)$ & $78(50.0)$ & $112(47.5)$ & $N / A$ \\
\hline Elevated $(\geq 93.95)^{a}$ & $46(57.5)$ & $78(50.0)$ & $124(52.5)$ & $N / A$ \\
\hline \multicolumn{5}{|l|}{ IGFBP-3 level (ng/mL) } \\
\hline Geometric mean (geometric s.d.) & $2069.3(1.25)$ & $1960.3(1.32)$ & $1996.6(1.30)$ & $N / A$ \\
\hline Median (IQR) & $2097(635)$ & $2009(652)$ & $2057(638)$ & $N / A$ \\
\hline$<2009$ & $34(42.5)$ & $78(50.0)$ & $112(47.5)$ & N/A \\
\hline Elevated $(\geq 2009)^{a}$ & $46(57.5)$ & $78(50.0)$ & $124(52.5)$ & $N / A$ \\
\hline
\end{tabular}

Abbreviations: BCFR Breast Cancer Family Registry, BMI body mass index, BOADICEA Breast and Ovarian Analysis of Disease Incidence and Carrier Estimation Algorithm, IGF-1 insulin-like growth factor 1, IGFBP-3 insulin-like growth factor binding protein 3, IQR interquartile range

aBiomarker elevation defined as greater than or equal to the median value in controls

${ }^{\mathrm{b}}$ Age at interview (blood draw N/A)

We did not find evidence of multiplicative interaction between elevated risk score and elevated IGF-1 (Table 2); each model showed increased risk, with roughly equivalent point estimates. Modest synergistic interaction was evident in women with high IGFBP-3 and high BOADICEA $(\mathrm{OR}=3.47,95 \% \mathrm{CI}=1.04-11.6)$ compared to women with low IGFBP-3 and low BOADICEA risk. This synergistic effect was stronger than the risk for women with high IGFBP-3 and low BOADICEA compared to low IGFBP-3 and low risk $(\mathrm{OR}=2.08,95 \% \mathrm{CI}=$ 0.55-7.92) and women with low IGFBP-3 and high BOADICEA compared to low IGFBP-3 and low risk 
Table 2 Breast cancer relative risk by biomarker level, New York Site of BCFR

\begin{tabular}{|c|c|c|}
\hline & \multicolumn{2}{|c|}{ Breast cancer relative risk } \\
\hline & $\mathrm{OR}^{\mathrm{a}}(95 \% \mathrm{Cl})$ & $\mathrm{OR}^{\mathrm{b}}(95 \% \mathrm{Cl})$ \\
\hline \multicolumn{3}{|l|}{ IGF-1 } \\
\hline \multicolumn{3}{|l|}{ Log-transformed continuous IGF-1 ( $N=236)$} \\
\hline & $1.19(0.52,2.70)$ & $0.77(0.26,2.31)$ \\
\hline \multicolumn{3}{|l|}{ Median IGF-1 in controls $(N=236)$} \\
\hline$<93.95 \mathrm{ng} / \mathrm{mL}$ & Reference & Reference \\
\hline \multirow[t]{2}{*}{ Elevated $(\geq 93.95 \mathrm{ng} / \mathrm{mL})$} & $1.46(0.80,2.71)$ & $1.37(0.66,2.85)$ \\
\hline & $\mathrm{OR}^{\mathrm{a}}(95 \% \mathrm{Cl})$ & $\mathrm{OR}^{\mathrm{c}}(95 \% \mathrm{Cl})$ \\
\hline \multicolumn{3}{|l|}{ Interaction with BOADICEA risk score $(N=231)$} \\
\hline Low IGF-1 $(<93.95)$, low BOADICEA risk $(<3.4 \%)(N=27)$ & Reference & Reference \\
\hline Elevated IGF-1 ( $\geq 93.95)$, low BOADICEA risk $(<3.4 \%)(N=48)$ & $2.49(0.72,8.63)$ & $2.76(0.64,11.9)$ \\
\hline Low IGF-1 (<93.95), high BOADICEA risk $(\geq 3.4 \%)(N=81)$ & $3.23(0.99,10.59)$ & $3.74(0.99,14.2)$ \\
\hline Elevated IGF-1 ( $\geq 93.95)$, high BOADICEA risk $(\geq 3.4 \%)(N=75)$ & $3.82(1.20,12.15)^{*}$ & $3.92(1.07,14.4)^{*}$ \\
\hline RERI & $-0.90(-4.22,2.41)$ & $-1.55(-5.80,2.69$ \\
\hline \multirow[t]{2}{*}{$p$ value for interaction } & 0.28 & 0.21 \\
\hline & $\mathrm{OR}^{\mathrm{a}}(95 \% \mathrm{Cl})$ & $\mathrm{OR}^{\mathrm{b}}(95 \% \mathrm{Cl})$ \\
\hline \multicolumn{3}{|l|}{ IGFBP-3 } \\
\hline \multicolumn{3}{|l|}{ Log-transformed continuous IGFBP-3 $(N=236)$} \\
\hline & $2.76(0.84,9.07)$ & $4.90(0.99,24.1)$ \\
\hline \multicolumn{3}{|l|}{ Median IGFBP-3 in controls $(N=236)$} \\
\hline$<2009$ & Reference & Reference \\
\hline \multirow[t]{2}{*}{ Elevated ( $\geq 2009$ ) } & $1.41(0.79,2.51)$ & $1.62(0.81,3.24)$ \\
\hline & $\mathrm{OR}^{\mathrm{a}}(95 \% \mathrm{Cl})$ & $\mathrm{OR}^{\mathrm{c}}(95 \% \mathrm{Cl})$ \\
\hline \multicolumn{3}{|l|}{ Interaction with BOADICEA risk score $(N=231)$} \\
\hline Low IGFBP-3 (< 2009), low BOADICEA risk $(<3.4 \%)(N=28)$ & Reference & Reference \\
\hline Elevated IGFBP-3 ( $\geq 2009)$, low BOADICEA risk $(<3.4 \%)(N=47)$ & $1.52(0.48,4.83)$ & $2.08(0.55,7.92)$ \\
\hline Low IGFBP-3 $(<2009)$, high BOADICEA risk $(\geq 3.4 \%)(N=81)$ & $2.09(0.71,6.13)$ & $2.26(0.70,7.25)$ \\
\hline Elevated IGFBP-3 ( $\geq 2009)$, high BOADICEA risk $(\geq 3.4 \%)(N=75)$ & $3.24(1.09,9.63)^{*}$ & $3.47(1.04,11.6)^{*}$ \\
\hline RERI & $0.63(-1.50,2.77)$ & $0.13(-2.60,2.86)$ \\
\hline$p$ value for interaction & 0.97 & 0.68 \\
\hline
\end{tabular}

Abbreviations: BCFR Breast Cancer Family Registry, Cl confidence interval, IGF-1 insulin-like growth factor 1, IGFBP-3 insulin-like growth factor binding protein 3, $R E R I$ relative excess risk due to interaction

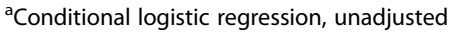

${ }^{\mathrm{b}}$ Conditional logistic regression, adjusted for age at blood draw, BMI, smoking status, alcohol consumption, menopausal status, continuous BOADICEA score, and opposing biomarker (IGF-1 or IGFBP-3)

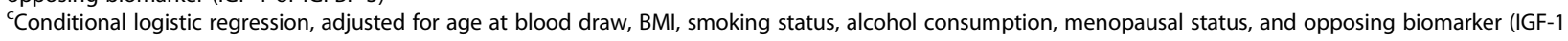
or IGFBP-3)

*Statistically significant

$(\mathrm{OR}=2.26,95 \% \mathrm{CI}=0.70-7.25)$ (Table 2). Neither the IGF-1 nor IGFBP-3 models demonstrated significant RERI (Table 2).

\section{Discussion}

We found an overall increased breast cancer risk for IGF-1 or IGFBP-3 elevation, although it was not statistically significant $(\geq$ median compared to $<$ : IGF-1 OR = 1.37, 95\% CI =0.66-2.85; IGFBP-3 OR $=1.62,95 \% \mathrm{CI}=$ $0.81-3.24)$. The magnitude of these associations is consistent with results from pooled analyses comparing women with the highest and lowest biomarker concentrations [2]; a pooled analysis of 17 prospective studies indicated a strong positive association between IGF-1 and breast cancer ( $p$ trend $<0.0001$ ), with an OR of 1.28 (1.14-1.44) for women in the highest IGF-1 quintile [2]. Increased breast cancer risk was also associated with IGFBP-3 elevation in this pooled analysis ( $p$ trend $=$ $0.062)$, with an OR of $1.13(0.99-1.28)$ at the highest IGFBP-3 quintile [2]. In the analyses restricted to 
women with a first-degree relative with breast cancer, the risk increased to an OR of $1.62(1.09-2.39)$ for women at the highest IGF-1 quintile and $\mathrm{OR}=1.35$ (0.92-1.99) for the highest IGFBP-3 quintile, further supporting the hypothesis that family history may be an important modifier [2]. We see similar increases in risk due to IGFBP-3 elevation alone and increased familial risk alone, and the combined effect of both was statistically significant $(\mathrm{OR}=3.47,95 \%$ CI $1.04-11.6$ for high IGFBP-3 and high BOADICEA).

Study limitations include the cohort sample size; despite the consistency of our effect estimates with prior literature, we had low power, particularly for subgroup analyses. None of the women in this sample had IGF-1 or IGFBP-3 levels outside the normal range; there were therefore no clinically defined thresholds to indicate abnormal elevation. In addition, we obtained a single baseline measure of IGF-1 and IGFBP-3. Intra-individual variability exists for IGF-1, and diet can modify nonfasted IGFBP-3 levels; single biomarker measures should be interpreted with caution [10].

The results of this study offer some support that blood biomarkers, particularly IGFBP-3, may be useful in improving risk stratification, especially if replicated in larger enriched cohorts $[9,11-13]$. There are fewer data on biomarkers for women at elevated breast cancer risk; these results suggest that elevated levels of IGF-1 and IGFBP-3 may be similarly related to breast cancer risk on a relative scale irrespective of absolute baseline risk. Given the higher absolute risk of breast cancer, the similar relative magnitude of risk may translate into a greater absolute risk difference from changes in these biomarkers.

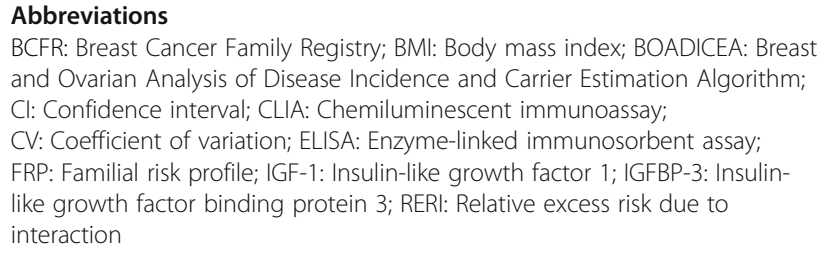

BCFR: Breast Cancer Family Registry; BMI: Body mass index; BOADICEA: Breast and Ovarian Analysis of Disease Incidence and Carrier Estimation Algorithm; Cl: Confidence interval; CLIA: Chemiluminescent immunoassay; CV: Coefficient of variation; ELISA: Enzyme-linked immunosorbent assay; FRP: Familial risk profile; IGF-1: Insulin-like growth factor 1; IGFBP-3: Insulinlike growth factor binding protein 3; RERI: Relative excess risk due to interaction

\section{Acknowledgements}

We are grateful to all of the participants of the Breast Cancer Family Registry (BCFR).

\section{Authors' contributions}

KM conducted the data analyses and drafted the initial manuscript. MG $\mathrm{HCW}$, and MBT contributed to the data analyses and writing. RPS, WKC, and MBT designed the parent study and led the data and biospecimen collection. All authors read and approved the final manuscript.

\section{Funding}

The New York site of the Breast Cancer Family Registry is supported by grants R01 CA 159868 and UM1 CA164920 from the US National Cancer Institute and ES009089. This work was also supported by the Breast Cancer Research Foundation. The content of this manuscript does not necessarily reflect the views or policies of the National Cancer Institute or any of the collaborating centers in the Breast Cancer Family Registry (BCFR), nor does mention of trade names, commercial products, or organizations imply endorsement by the USA Government or the BCFR.

\section{Availability of data and materials}

The datasets used and/or analyzed during the current study are available from the corresponding author on reasonable request.

\section{Ethics approval and consent to participate}

All women participating in the BCFR provided written informed consent, and the study was approved by the Columbia University Medical Center Institutional Review Board.

\section{Consent for publication}

Not applicable.

\section{Competing interests}

The authors declare that they have no competing interests.

\section{Author details}

${ }^{1}$ Department of Epidemiology, Mailman School of Public Health, Columbia University, 722 West 168th Street, New York, NY 10032, USA. ²Department of Environmental Health Sciences, Mailman School of Public Health, Columbia University, 722 West 168th Street, New York, NY 10032, USA. ${ }^{3}$ Herbert Irving Comprehensive Cancer Center, Columbia University Medical Center, 1130 St. Nicholas Avenue, New York, NY 10032, USA. ${ }^{4}$ Department of Pediatrics, Columbia University, 622 West 168th Street, New York, NY, USA. ${ }^{5}$ Department of Medicine, Columbia University Medical Center, 630 West 168th Street, New York, NY, USA.

Received: 11 June 2020 Accepted: 7 October 2020

Published online: 22 October 2020

\section{References}

1. Wen YY, et al. IGF-1-mediated PKM2/beta-catenin/miR-152 regulatory circuit in breast cancer. Sci Rep. 2017;7(1):15897.

2. Key TJ, et al. Insulin-like growth factor 1 (IGF1), IGF binding protein 3 (IGFBP3), and breast cancer risk: pooled individual data analysis of 17 prospective studies. Lancet Oncol. 2010;11(6):530-42.

3. Goodwin PJ, et al. Insulin-like growth factor binding proteins 1 and 3 and breast cancer outcomes. Breast Cancer Res. 2002;74(1):65-76.

4. Terry MB, et al. Cohort profile: the breast cancer prospective family study cohort (ProF-SC). Int J Epidemiol. 2016;45(3):683-92.

5. Shen J, et al. Dependence of cancer risk from environmental exposures on underlying genetic susceptibility: an illustration with polycyclic aromatic hydrocarbons and breast cancer. Br J Cancer. 2017;116(9):1229-33.

6. John EM, et al. The Breast Cancer Family Registry: an infrastructure for cooperative multinational, interdisciplinary and translational studies of the genetic epidemiology of breast cancer. Breast Cancer Res. 2004;6(4):R375-89.

7. Antoniou AC, et al. The BOADICEA model of genetic susceptibility to breast and ovarian cancers: updates and extensions. Br J Cancer. 2008;98(8):1457-66.

8. Terry MB, et al. 10-year performance of four models of breast cancer risk: a validation study. Lancet Oncol. 2019;20(4):504-17.

9. Quante AS, et al. Practical problems with clinical guidelines for breast cancer prevention based on remaining lifetime risk. J Natl Cancer Inst. 2015;107(7):1-7

10. Milani $D$, et al. Variability and reliability of single serum IGF-I measurements: impact on determining predictability of risk ratios in disease development. J Clin Endocrinol Metab. 2004;89(5):2271-4.

11. Quante AS, et al. Assessing absolute changes in breast cancer risk due to modifiable risk factors. Breast Cancer Res Treat. 2015;152(1):193-7.

12. Quante AS, et al. Breast cancer risk assessment across the risk continuum: genetic and nongenetic risk factors contributing to differential model performance. Breast Cancer Res. 2012;14(6):R144.

13. Gong $\mathrm{G}$, et al. Assessing the goodness of fit of personal risk models. Stat Med. 2014:33(18):3179-90.

\section{Publisher's Note}

Springer Nature remains neutral with regard to jurisdictional claims in published maps and institutional affiliations. 